\title{
PENGOLAHAN LIMBAH LABORATORIUM LINGKUNGAN FAKULTAS TEKNIK DENGAN KOMBINASI PROSES KIMIA DAN BIOLOGI \\ Nina Yohana ${ }^{1}$ Arifin $^{1}$ Lia Destiarti ${ }^{2}$ \\ ${ }^{1}$ Program Studi Teknik Lingkungan Jurusan Teknik Sipil Fakultas Teknik Universitas Tanjungpura, Pontianak \\ ${ }^{2}$ Program Studi Kimia Jurusan Kimia Fakultas Matematika dan IImu Pengetahuan Alam Universitas \\ Tanjungpura, Pontianak \\ Email: ninayohana06@gmail.com
}

\begin{abstract}
ABSTRAK
Limbah laboratorium merupakan limbah yang berasal dari buangan hasil reaksi-reaksi berbagai larutan kimia dalam suatu eksperimen. Laboratorium Lingkungan Fakultas Teknik Universitas Tanjungpura merupakan laboratorium yang belum memiliki pengolahan. Hal ini akan berdampak pada lingkungan jika dibuang langsung tanpa proses pengolahan limbah terlebih dahulu. Dalam penelitian ini dilakukan proses pengolahan limbah cair Laboratorium Lingkungan Fakultas Teknik dengan kombinasi proses kimia dan biologi yang bertujuan untuk menurunkan parameter Chemical Oxygen Demand (COD), Fe dan Pb agar sesuai dengan baku mutu menurut PERMEN LH No.5 Th 2014 serta mengidentifikasi efektivitas pengolahan limbah cair Laboratorium Lingkungan Fakultas Teknik. Pengolahan dilakukan dengan dua perlakuan. Perlakuan ke-I yaitu proses netralisasi menggunakan soda ash $\left(\mathrm{Na}_{2} \mathrm{CO}_{3}\right)$, koagulasi menggunakan tawas dan adsorpsi menggunakan adsorben zeolit dan karbon aktif, serta proses fitoremediasi mengggunakan eceng gondok, sedangkan pada perlakuan ke-Il proses fitoremediasi dilakukan terlebih dahulu sebelum proses adsorpsi. Berdasarkan uji pendahuluan nilai $\mathrm{pH}$ pada perlakuan ke-I sebelum dilakukan proses pengolahan yaitu 1,3, COD sebesar 1617,1 mg/l, Fe sebesar 12,59 mg/l dan Pb sebesar $6,75 \mathrm{mg} / \mathrm{l}$. Kondisi sampel awal sebelum dilakukan proses pengolahan pada perlakuan ke-II memiliki nilai pH 1,2, COD sebesar $1635,3 \mathrm{mg} / \mathrm{l}$, Fe sebesar 8,46 mg/l dan Pb sebesar 7,36 mg/l. Nilai tersebut masih diatas baku mutu PERMEN LH No.5 Th 2014 yaitu konsentrasi COD sebesar $100 \mathrm{mg} / \mathrm{l}$, Fe sebesar $5 \mathrm{mg} / \mathrm{l}$ dan Pb sebesar 0,1 mg/l. Pengolahan ini dilakukan dengan sistem batch dalam skala laboratorium dan dilakukan tiga kali ulangan dalam setiap perlakuan. Perlakuan ke-I memiliki efektivitas rata-rata dalam penurunan parameter COD sebesar $89 \%$ yaitu dari $1617,1 \mathrm{mg} / \mathrm{l}$ menjadi 161,9 mg/l, logam Fe 79\% dari 12,6 mg/l menjadi 2,59 mg/l dan logam $\mathrm{Pb}$ sebesar $99 \%$ dari $6,75 \mathrm{mg} / \mathrm{l}$ menjadi $0,064 \mathrm{mg} / \mathrm{l}$. Sedangkan pada perlakuan ke-Il efektivitas rata-rata penurunan COD yaitu sebesar $86 \%$ dari $1635,3 \mathrm{mg} / \mathrm{l}$ menjadi $233,6 \mathrm{mg} / \mathrm{l}$, logam Fe $53 \%$ dari 8,46 mg/l menjadi 3,94 mg/l dan logam Pb sebesar $99 \%$ dari 7,36 mg/l menjadi 0,043 mg/l. Nilai pH limbah yang dihasilkan pada perlakuan ke-I dari 1,3 menjadi 7,8 dan pada perlakuan ke-II dari 1,2 menjadi 7,8. Berdasarkan nilai efektivitas yang diperoleh dari dua perlakuan tersebut dapat diketahui bahwa nilai COD yang dihasilkan masih diatas baku mutu. Karena dalam penelitian ini tidak dilakukan analisis uji besaran parameter per unit pengolahan, sehingga tidak diketahui unit pengolahan yang lebih spesifik dalam penurunan parameter COD. Oleh sebab itu, disarankan dapat melengkapi penelitian dengan menguji besaran parameter per unit pengolahan.
\end{abstract}

Kata Kunci : Limbah Cair Laboratorium, Proses Kimia, Proses Biologi

\begin{abstract}
Laboratory wastewater is various discharges of waste containing chemical solution from analysis activity. Environmental laboratory in Universitas Tanjungpura is a laboratory that has not had wastewater treatment processing. This will give impact directly on the environment if disposed of without treated. In this research, are build the process of wastewater treatment at the Laboratory of the environmental Faculty of Engineering using a combination of chemical and biological processes are aimed to reduce the parameters Chemical Oxygen Demand (COD), Fe and $P b$ comply with quality standards according to PERMEN LH $5^{\text {th }} 2014$ and to identify the effectiveness of treatment liquid waste Environmental Laboratory Faculty of Engineering. Treatment processing is done with the two treatments. The first treatment is the neutralization process using soda ash
\end{abstract}


$\left(\mathrm{Na}_{2} \mathrm{CO}_{3}\right)$, coagulation using alum and adsorption using zeolite adsorbent and activated carbon, and phytoremediation process using water hyacinth, while in the second treatment phytoremediation process done first before adsorption process. Based on the preliminary test the $\mathrm{pH}$ value of first treatment prior to the processing of 1.3, COD amounted to $1617.1 \mathrm{mg} / \mathrm{l}$, Fe of $12.59 \mathrm{mg} / \mathrm{I}$ and $6.75 \mathrm{mg} \mathrm{Pb/l}$. Conditions initial sample prior to the processing of the second treatment has a pH value of 1.2, COD amounted to $1635.3 \mathrm{mg} / \mathrm{l}$, Fe by $8.46 \mathrm{mg} / \mathrm{l}$ and $\mathrm{Pb}$ at 7.36 $\mathrm{mg} / \mathrm{I}$. The value is still above the standard of PERMEN LH 5th 2014 which is a COD concentration of $100 \mathrm{mg} / \mathrm{l}$, Fe of $5 \mathrm{mg} / \mathrm{l}$ and $\mathrm{Pb}$ of $0.1 \mathrm{mg} / \mathrm{l}$. This wastewater treatment is done by the system on a laboratory scale batch and do three replications in each treatment. The first treatment had a mean effectiveness in the decrease of COD parameters of 89\% is from 1617 to $1 \mathrm{mg} / \mathrm{I}$ to 161.9 $\mathrm{mg} / \mathrm{l}$, Fe metal 79\% from 12 to $6 \mathrm{mg} / \mathrm{I}$ to $2.59 \mathrm{mg} / \mathrm{I}$ and Pb metal of 99\% from 6 to $75 \mathrm{mg} / \mathrm{I}$ to $0.064 \mathrm{mg} / \mathrm{l}$. While in the second treatment effectiveness average COD reduction in the amount of $86 \%$ of $1635.3 \mathrm{mg} / \mathrm{I}$ to $233.6 \mathrm{mg} / \mathrm{l}, 53 \%$ Fe metals of $8.46 \mathrm{mg} / \mathrm{I}$ to $3.94 \mathrm{mg} / \mathrm{I}$ and $\mathrm{Pb}$ amounting to $99 \%$ of the $7.36 \mathrm{mg} / \mathrm{I}$ to $0.043 \mathrm{mg} / \mathrm{I}$. The $\mathrm{pH}$ value of waste generated in the first treatment from 1.3 to 7.8 and at the second treatment from 1.2 to 7.8. Based on the effectiveness, the value obtained from the two treatments it can be seen that the value of COD produced is still above the standard quality. Moreover, this research is non-quantity parameter test analysis of each processing unit which makes this study provides limited measured information is available on the specific effectively evaluate COD decline. In additional of that, the author recommends for future research should include information in specific effectively evaluate on each unit treatment.

Key Words: Liquid Waste Laboratory, Chemical Process, Biological Process

\section{PENDAHULUAN}

Limbah laboratorium merupakan limbah yang berasal dari buangan hasil reaksireaksi berbagai larutan kimia dalam suatu eksperimen. Limbah laboratorium mengandung jenis senyawa-senyawa organik dan logam. Hal ini akan berdampak pada lingkungan jika dibuang langsung tanpa proses pengolahan limbah terlebih dahulu. Limbah yang berasal dari laboratorium lingkungan Fakultas Teknik Universitas Tanjungpura merupakan limbah yang dihasilkan dari berbagai kegiatan praktikum dan belum dilakukan pengolahan.

Pengolahan limbah laboratorium lingkungan dapat dilakukan dengan proses koagulasi dan adsorpsi. Pengolahan limbah dengan proses koagulasi bertujuan untuk menurunkan parameter Chemical Oxygen Demand (COD), sedangkan proses pengolahan menggunakan proses adsorpsi bertujuan untuk menurunkan logam $\mathrm{Fe}$ dan logam $\mathrm{Pb}$ (Audiana 2016 ; Azamia 2012).

Berdasarkan penelitian Audiana (2016), efisiensi penurunan parameter COD sebesar 59,81\% dari $611,4 \mathrm{mg} / \mathrm{l}$ menjadi $245,7 \mathrm{mg} / \mathrm{l}$, logam Fe $62,25 \%$ dari $194 \mathrm{mg} / \mathrm{l}$ menjadi $7,324 \mathrm{mg} / \mathrm{l}$, logam $\mathrm{Pb}$ sebesar $71,13 \%$ dari $22,9 \mathrm{mg} / \mathrm{l}$ menjadi $6,612 \mathrm{mg} / \mathrm{l}$. Menurut Peraturan Menteri Lingkungan Hidup No.5 Th. 2014 tentang Baku Mutu Air Limbah untuk golongan I yang dapat dibuang ke lingkungan yaitu COD sebesar $100 \mathrm{mg} / \mathrm{l}$, Fe sebesar $5 \mathrm{mg} / \mathrm{I}$ dan $\mathrm{Pb}$ sebesar 0,1 mg/l. Hal tersebut karena $\mathrm{pH}$ limbah Laboratorium Lingkungan masih dalam kondisi asam. Oleh karena itu, perlu dilakukan pengolahan awal seperti proses netralisasi serta dilakukan pengolahan lanjutan yaitu proses fitoremediasi menggunakan tumbuhan eceng gondok yang bertujuan untuk menurunkan parameter $\mathrm{COD}$, $\mathrm{Fe}$ dan $\mathrm{Pb}$ agar sesuai dengan baku mutu menurut PERMEN LH No.5 Th 2014 serta mengidentifikasi efektivitas pengolahan limbah cair Laboratorium Lingkungan Fakultas Teknik.

\section{METODOLOGI PENELITIAN}

Penelitian ini dilakukan selama satu bulan yaitu dari bulan juni hingga juli 2017. Pembuatan dan pengoperasian alat dilakukan di Laboratorium Lingkungan Program 
Studi Teknik Lingkungan Fakultas Teknik Universitas Tanjungpura. Pengujian sampel dilakukan di Laboratorium Pertanian Universitas Tanjungpura.

Alat yang digunakan dalam penelitian yaitu 1 buah gelas beaker $100 \mathrm{ml}$ dan 6 buah gelas beaker $1000 \mathrm{ml}$, reaktor $20 \mathrm{~L}$ sebanyak 5 buah, penggaris $30 \mathrm{~cm} 1$ buah, batang pengaduk 1 buah dan drum penampung dengan volume 120 liter. Spektrofotometer Serapan Atom SHIMADZU AA-6300 untuk mengetahui kadar logam berat, Spectrofotometer DR $2800 \mathrm{HACH}$ untuk mengetahui kadar COD, pH meter 1 buah, sedangkan bahan yang digunakan yaitu limbah cair laboratorium sebanyak 10 liter untuk setiap ulangan, soda ash sebanyak 210 gram, koagulan tawas sebanyak 3,3 kg, adsorben zeolit dan karbon aktif masing-masing sebanyak $1,5 \mathrm{~kg}$, serta eceng gondok.

Sebelum dilakukan proses pengolahan limbah dengan dua proses perlakuan terlebih dahulu dilakukan uji pendahuluan untuk mengetahui banyaknya soda ash yang digunakan dalam proses netralisasi dan dilakukan uji jartest untuk menentukan konsentrasi koagulan yang digunakan. Variasi dosis koagulan yang digunakan dalam uji jartest yaitu 0,28 g, 0,29 g, 0,3 g, 0,31 g, 0,32 g dan 0,33 g untuk $100 \mathrm{ml}$ air limbah. kecepatan pengadukan yang digunakan adalah $100 \mathrm{rpm}$ sebagai pengadukan cepat selama 1 menit, $40 \mathrm{rpm}$ sebagai pengadukan lambat selama 15 menit, dan 30 menit tanpa pengadukan.

Proses pengolahan limbah laboratorium dilakukan dengan dua perlakuan. Proses pengolahan yang dilakukan dalam perlakuan ke-I yaitu proses netralisasi menggunakan soda ash sebanyak 210 gram dalam 4,2 liter akuades untuk meningkatkan pH menjadi 7,8 . Proses kedua yaitu proses koagulasi menggunakan koagulan tawas sebanyak $3,3 \mathrm{~kg}$. Proses selanjutnya yaitu proses adsorpsi menggunakan adsorben zeolit dan karbon aktif masing-masing sebanyak $1,5 \mathrm{~kg}$, dan proses terakhir yaitu proses fitoremediasi menggunakan tumbuhan eceng gondok. Sebelum digunakan dalam proses pengolahan limbah, tumbuhan eceng gondok terlebih dahulu dilakukan aklimatisasi menggunakan air bersih selama tiga hari. Tumbuhan eceng gondok yang digunakan adalah tumbuhan dengan jumlah helai daun tiap rumpun 4-6 helai sebanyak 8 rumpun dengan tinggi batang $15-30 \mathrm{~cm}$, untuk mengetahui pengaruhnya terhadap penurunan kandungan logam pada air limbah laboratorium yang telah diolah dilakukan pengamatan dan pengujian limbah setelah hari ke-8. Proses pengolahan yang dilakukan pada perlakuan ke-II yaitu sama halnya dengan perlakuan ke-I, akan tetapi pada perlakuan ke-II proses fitoremediasi dilakukan terlebih dahulu sebelum proses adsorpsi. Setiap perlakuan dilakukan tiga kali pengulangan dengan volume limbah yang digunakan sebanyak 10 liter untuk setiap ulangannya.

Analisis data dilakukan dengan metode deskriftif komparatif, dimana kualitas air limbah laboratorium yang telah dilakukan pengolahan dibandingkan dengan kualitas air limbah laboratorium sebelum dilakukan pengolahan untuk mendapatkan nilai efektivitas yang disajikan dalam bentuk tabel, selain itu penelitian ini juga menggunakan analisa data uji statistik non parametrik dengan menggunakan jenis metode uji Mann Whitney menggunakan software Minitab14.

\section{HASIL DAN PEMBAHASAN}

Limbah yang digunakan dalam penelitian ini merupakan limbah cair hasil praktikum di Laboratorium Teknik Lingkungan Fakultas Teknik Universitas Tanjungpura. Praktikum yang dilakukan diantaranya menggunakan bahan seperti $\mathrm{AgNO}_{3}, \mathrm{~Pb}\left(\mathrm{NO}_{3}\right)_{2}$, $\mathrm{NaCl}, \mathrm{KMnO}_{4}$ dan lain-lain. Berdasarkan bahan yang digunakan dalam praktikum tersebut limbah laboratorium lingkungan memiliki kadar logam $\mathrm{Fe}, \mathrm{Pb}$ dan $\mathrm{COD}$ yang melebihi baku mutu. Hasil analisis sampel awal sebelum pengolahan dapat dilihat pada Tabel 1 : 
Tabel 1 Kandungan Limbah Laboratorium Lingkungan

\begin{tabular}{ccccc}
\hline \multirow{2}{*}{ Parameter } & Satuan & Baku & \multicolumn{2}{c}{ Hasil Analisis Sampel Awal } \\
\cline { 4 - 5 } & Mutu* & $\begin{array}{c}\text { Sebelum } \\
\text { Perlakuan ke-I }\end{array}$ & $\begin{array}{c}\text { Sebelum } \\
\text { Perlakuan ke-II }\end{array}$ \\
\hline COD & $\mathrm{mg} / \mathrm{l}$ & 100 & 1617,1 & 1635,3 \\
Besi (Fe) & $\mathrm{mg} / \mathrm{l}$ & 5 & 12,59 & 8,46 \\
Timbal $(\mathrm{Pb})$ & $\mathrm{mg} / \mathrm{l}$ & 0,1 & 6,75 & 7,36 \\
\hline
\end{tabular}

* PERMEN LH No 5 Tahun 2014

A. Pengolahan Limbah Laboratorium

$>\quad$ Uji Pendahuluan

Soda ash yang digunakan dalam proses netralisasi yaitu soda ash dalam bentuk bubuk, sehingga perlu dilarutkan terlebih dahulu dengan akuades sebelum digunakan. Reaksi kimia yang terjadi yaitu sebagai berikut :

$$
\mathrm{Na}_{2} \mathrm{CO}_{3}+\mathrm{H}_{2} \mathrm{O} \longrightarrow \mathrm{H}_{2} \mathrm{CO}_{3}+2 \mathrm{NaOH}
$$

Berikut merupakan tabel penentuan banyaknya soda ash yang digunakan dalam proses netralisasi:

\begin{tabular}{|c|c|}
\hline $\begin{array}{c}\text { Volume Soda Ash } \\
(0,47 \mathrm{M})\end{array}$ & $\mathrm{pH}$ \\
\hline 100 & 2,1 \\
\hline 200 & 6,9 \\
\hline 250 & 7,8 \\
\hline
\end{tabular}

Berdasarkan Tabel 2 dapat diketahui bahwa untuk menetralkan limbah hingga mencapai pH 7,8 menggunakan volume soda ash $0,47 \mathrm{M}$ sebanyak $250 \mathrm{ml}$.

Penentuan Dosis Koagulan

Kagulan yang digunakan dalam proses koagulasi yaitu koagulan tawas. Variasi dosis koagulan yang digunakan dalam uji jartest yaitu $0,28 \mathrm{~g}, 0,29 \mathrm{~g}, 0,3 \mathrm{~g}, 0,31 \mathrm{~g}, 0,32 \mathrm{~g}$ dan $0,33 \mathrm{~g}$ untuk $100 \mathrm{ml}$ air limbah. Kecepatan pengadukan yang digunakan adalah 100 rpm untuk pengadukan cepat selama 1 menit, $40 \mathrm{rpm}$ sebagai pengadukan lambat selama 15 menit dan 30 menit tanpa pengadukan. Setelah itu dilakukan pengukuran kekeruhan dengan menggunakan turbidimeter. Dari penentuan dosis tawas didapat nilai kekeruhan seperti pada Tabel 3.

\begin{tabular}{cc} 
Tabel 3 Pengaruh Dosis Koagulan Terhadap Nilai Kekeruh \\
\hline Dosis Koagulan & Kekeruhan (NTU) \\
\hline 0,28 & 41,3 \\
0,29 & 37,2 \\
0,30 & 20,3 \\
0,31 & 16,63 \\
0,32 & 24,5 \\
0,33 & 15,95 \\
\hline
\end{tabular}

Berdasarkan Tabel 3 dapat diketahui bahwa nilai kekeruhan terendah yaitu 15,95 NTU dengan dosis tawas 0,33 gram. Sehingga dosis tawas yang digunakan dalam proses pengolahan limbah yaitu 0,33 gram per $10 \mathrm{ml}$ akuades. Berdasarkan penelitian Azamia 
(2012) menyatakan bahwa semakin kecil nilai kekeruhan maka semakin baik pula untuk proses pengolahan ke tahap selanjutnya.

B. Proses Pengolahan Limbah Laboratorium dengan Kombinasi Proses Kimia dan Biologi

$>$ Perlakuan ke-I

Proses yang dilakukan pada perlakuan ke-I yaitu proses netralisasi, koagulasi, adsorpsi dan fitoremediasi.

- $\quad$ Netralisasi

Netralisasi merupakan proses yang digunakan untuk menetralkan limbah cair yang bersifat asam atau basa. Berdasarkan penelitian Audiana (2016), limbah laboratorium yang diolah masih diatas baku mutu. Salah satu penyebabnya yaitu limbah cair laboratorium lingkungan masih dalam kondisi asam dengan $\mathrm{pH} \mathrm{3,16.} \mathrm{Oleh} \mathrm{karena} \mathrm{itu}$ dalam penelitian ini dilakukan proses netralisasi $\mathrm{pH}$ menggunakan larutan soda ash $\left(\mathrm{Na}_{2} \mathrm{CO}_{3}\right)$ sebelum dilakukan proses koagulasi. Nilai $\mathrm{pH}$ limbah awal sebelum proses netralisasi memiliki pH asam yaitu sebesar 1,3. Menurut Azamia (2012), dalam proses koagulasi koagulan dapat bekerja dengan baik pada $\mathrm{pH}$ optimum yaitu pada $\mathrm{pH} 6-7,8$. Oleh karena itu, dalam proses pengolahan ini dilakukan proses netralisasi $\mathrm{pH}$ limbah terlebih dahulu hingga $\mathrm{pH}$ mencapai 7,8 .

- Koagulasi

Koagulasi merupakan peristiwa destabilisasi dari partikel-partikel koloid dimana gaya tolak-menolak diantara partikel dikurangi. Proses koagulasi dalam penelitian ini menggunakan koagulan tawas $\left(\mathrm{Al}_{2}\left(\mathrm{SO}_{4}\right)_{3}\right)$ untuk menurunkan parameter $\mathrm{COD}$ (Chemical Oxygen Demand). Berdasarkan hasil analisis pada perlakuan ke-I dapat diketahui bahwa nilai rata-rata parameter COD sebelum proses pengolahan yaitu sebesar $1617,1 \mathrm{mg} / \mathrm{l}$ dan nilai rata-rata COD setelah proses pengolahan yaitu $161,9 \mathrm{mg} / \mathrm{l}$. Nilai rata-rata parameter tersebut masih diatas baku mutu yang diizinkan menurut PERMEN LH No. 5 Tahun 2014. Hal tersebut karena dapat dipengaruhi oleh beberapa faktor salah satunya yaitu kondisi pengadukan. Pengolahan limbah laboratorium pada penelitian ini menggunakan proses koagulasi dengan cara pengadukan manual. Menurut penelitian Azamia (2012), pada proses koagulasi seharusnya pengadukan dilakukan dengan cepat. Pengadukan pada proses koagulasi berfungsi untuk menyempurnakan tumbukan antar partikel untuk netralisasi menjadi sempurna. Pembentukan flok juga dipengaruhi oleh proses pengadukan. Dimana semakin lama pengadukan maka pembentukan flok juga akan berlangsung lama, tetapi jika pengadukan berlangsung dengan terlalu cepat maka dapat mengakibatkan flok-flok yang terbentuk menjadi pecah.

Berdasarkan penelitian Aziz, dkk (2013), terjadinya penurunan bahan kimia organik maupun anorganik dalam koagulasi menggunakan tawas $\left(\mathrm{Al}_{2}\left(\mathrm{SO}_{4}\right)_{3}\right)$ dapat berpengaruh terhadap penurunan nilai COD pada limbah. Hal ini disebabkan kation AI pada tawas akan mengalami reaksi hidrolisis untuk membentuk endapan alumunium hidroksida. Alumunium terlarut yang terbentuk berupa monomer dan beberapa diantaranya bermuatan positif yang dapat menetralkan partikel koloid yang bermuatan negatif. Kandungan organik yang bersifat negatif cenderung teradsorpsi dan terperangkap dalam endapan alumunium hidroksida (Sutapa, 2014). Hal ini yang menyebabkan nilai COD pada limbah menjadi turun. Berikut reaksi yang terjadi karena adanya penambahan tawas dalam proses pengolahan limbah cair laboratorium:

$$
\mathrm{Al}_{2}\left(\mathrm{SO}_{4}\right)_{3}+6 \mathrm{H}_{2} \mathrm{O} \longrightarrow 2 \mathrm{Al}(\mathrm{OH})_{3}+6 \mathrm{H}^{+}+\mathrm{SO}_{4}{ }^{2-}
$$

Penambahan tawas pada proses koagulasi menyebabkan $\mathrm{pH}$ limbah menjadi lebih rendah dimana $\mathrm{pH}$ awal limbah setelah proses netralisasi yaitu 7,8 menjadi 6,5 . Hal ini 
dikarenakan tawas yang apabila dilarutkan dalam air akan melepaskan lebih banyak $\mathrm{H}^{+}$ yang menyebabkan pH limbah semakin menurun (Aziz, dkk. 2013).

\section{- $\quad$ Adsorpsi}

Proses adsorpsi dalam pengolahan limbah cair laboratorium menggunakan adsorben zeolit dan karbon aktif untuk menurunkan parameter $\mathrm{COD}$, logam $\mathrm{Fe}$ dan $\mathrm{Pb}$. Berdasarkan hasil analisis pada perlakuan ke-I diperoleh rata-rata penurunan logam Fe yaitu sebesar $2,59 \mathrm{mg} / \mathrm{l}$. Proses adsorpsi yang terjadi pada karbon aktif yaitu proses adsorpsi secara fisika, dimana proses penjerapan ion logam $\mathrm{Fe}^{2+}$ terjadi pada permukaan karbon aktif. Dengan adanya gaya Van Der Waals pada pori-pori karbon aktif maka partikel pencemar yang terdapat pada limbah tertarik dan terperangkap pada pori-pori karbon aktif sehingga ion logam $\mathrm{Fe}^{2+}$ pada limbah menjadi berkurang (Hendra, 2008). Nilai penurnunan rata-rata parameter $\mathrm{Pb}$ pada perlakuan ke-I yaitu sebesar 0,064 mg/l. Mekanisme penjerapan menggunakan zeolit, ion logam $\mathrm{Pb}^{2+}$ yang terdapat pada limbah laboratorium terjerap oleh pori permukaan zeolit dan bersubstitusi dengan kation $\mathrm{H}^{+}$ yang terdapat pada permukaan zeolit seperti pada reaksi berikut ini: (Prayitno, dkk, 2006)

$$
\text { Zeolit }-\mathrm{H}^{+}+\mathrm{Pb}^{2+} \longrightarrow \text { Zeolit }-\mathrm{Pb}^{2+}+\mathrm{H}^{+}
$$

Berdasarkan reaksi tersebut dapat dilihat bahwa terjadi pertukaran ion antara ion logam $\mathrm{Pb}^{2+}$ dengan kation $\mathrm{H}^{+}$yang menyebabkan ion logam $\mathrm{Pb}^{2+}$ terperangkap di dalam pori zeolit. Hal ini dikarenakan permukaan silika $\left(\mathrm{SiO}_{2}\right)$ mempunyai afinitas yang tinggi terhadap ion logam $\mathrm{Pb}^{2+}$. Atom oksigen yang berikatan dengan ion silika yang mempunyai sifat kebasaan yang rendah dan membuat permukaan silika bersifat asam lemah. Bentuk oksida yang lain juga bebas bereaksi dengan air membentuk hidroksida. Ion $\mathrm{H}^{+}$pada bentuk hidroksida akan melemah dan mudah lepas dan mengakibatkan ion logam $\mathrm{Pb}^{2+}$ akan terikat dan teradsorpsi secara kuat (Setiaka, dkk. 2010). Hal ini yang menyebabkan kadar $\mathrm{Pb}$ pada limbah menjadi turun, sedangkan kation $\mathrm{H}^{+}$yang terdapat pada permukaan zeolit terlepas dan menyebabkan $\mathrm{pH}$ limbah menjadi asam.

- $\quad$ Fitoremediasi

Fitoremediasi adalah sebuah teknologi yang menggunakan berbagai tanaman untuk menurunkan, mengekstrak atau menghilangkan kontaminan dari tanah dan air (EPA, 2000). Dalam pengolahan limbah laboratorium lingkungan proses fitoremediasi menggunakan tumbuhan eceng gondok sebagai penyerap kontaminan yang terdapat dalam limbah seperti COD, logam Fe dan $\mathrm{Pb}$. Nilai rata-rata parameter COD setelah proses pengolahan pada perlakuan ke-I yaitu sebesar 161,9 mg/l, logam Fe sebesar 2,59 $\mathrm{mg} / \mathrm{l}$ dan logam $\mathrm{Pb}$ sebesar $0,064 \mathrm{mg} / \mathrm{l}$. Kondisi tanaman eceng gondok setelah hari ke-8 proses fitoremediasi pada perlakuan ke-I mengalami kematian. Hal tersebut karena tanaman eceng gondok mengalami proses fitoekstraksi. Fitoekstrasi merupakan proses tumbuhan menarik zat kontaminan dari media sehingga berakumulasi di sekitar akar tumbuhan, proses ini juga disebut hiperaccumulation. Tanaman hiperakumulator merupakan jenis-jenis tanaman atau tumbuhan yang mampu mentranslokasikan unsurunsur tertentu dengan konsentrasi tinggi ke rendah tanpa membuat tanaman tersebut tumbuh dengan tidak normal dalam arti kata tidak kerdil (Oppelt, 2000).

Perlakuan Ke-II

Proses yang dilakukan pada perlakuan ke-I yaitu proses netralisasi, koagulasi, fitoremediasi dan adsorpsi.

- $\quad$ Netralisasi

Proses netralisasi pada perlakuan ke-II menggunakan rata-rata larutan soda ash yaitu sebanyak 4066,7 ml. Proses pengolahan limbah laboratorium pada perlakuan ke-II menggunakan larutan soda ash lebih banyak daripada perlakuan ke-I. Hal tersebut 
karena pada perlakuan ke-II kondisi limbah laboratorium memiliki $\mathrm{pH}$ yang lebih asam dari pH limbah saat perlakuan ke-I, yaitu dengan pH 1,2. Pada proses pengolahan limbah cair laboratorium lingkungan untuk setiap ulangan dalam proses netralisasi menggunakan $210 \mathrm{gr}$ soda ash yang dilarutakan dalam 4,2 liter akuades untuk menetralkan setiap 10 liter limbah cair laboratorium.

- Koagulasi

Proses kedua pada perlakuan ke-II dalam pengolahan limbah cair laboratorium yaitu proses koagulasi. Sama halnya dengan proses koagulasi pada perlakuan ke-I, koagulan yang digunakan yaitu koagulan tawas. Pada perlakuan ke-II nilai penurunan parameter COD lebih kecil daripada perlakuan ke-I. Dimana nilai penurunan rata-rata COD pada perlakuan ke-II yaitu sebesar $233,6 \mathrm{mg} / \mathrm{l}$. Koagulan yang digunakan untuk mengolah 10 liter air limbah dalam proses koagulasi untuk setiap ulangannya yaitu sebanyak $3,3 \mathrm{~kg}$ yang dilarutkan dengan akuades sebanyak 1 liter. Selain proses pengadukan dalam proses pengendapan selama 15 menit kondisi limbah tidak mengendap dengan baik, hal tersebut juga dapat mempengaruhi warna limbah yang tidak terjadi perubahan yaitu masih berwarna merah muda. Berdasarkan penelitian Azamia (2012), menyatakan bahwa semakin kecil nilai kekeruhan maka semakin baik pula untuk proses pengolahan ke tahap selanjutnya, karena koloid yang terkandung dalam sampel limbah cair berkurang. Warna limbah tersebut berdampak pula pada hasil proses koagulasi yang masih menghasilkan nilai COD diatas baku mutu.

- $\quad$ Fitoremediasi

Proses fitoremediasi pada perlakuan ke-Il dilakukan terlebih dahulu sebelum proses adsorpsi. Hal ini bertujuan membantu adsorben yang digunakan dalam proses adsorpsi agar tidak mudah jenuh dalam mengadsorpsi limbah yang diolah. Kondisi eceng gondok pada perlakuan ke-II setelah hari ke-8 mengalami kematian yang lebih cepat daripada saat fitoremediasi pada perlakuan ke-I. Karena pada saat hari ke- 6 eceng gondok telah mengalami kekeringan pada daun dan batang. Kondisi eceng gondok tersebut juga dapat mempengaruhi hasil pengolahan. Dimana penurunan parameter pencemar pada perlakuan ke-II lebih rendah daripada perlakuan ke-I. Hal tersebut karena eceng gondok mampu menyerap kontaminan yang terdapat dalam air limbah dengan bantuan akar untuk menyerapnya. Kontaminan yang diserap oleh akar tersebut kemudian diakumulasikan didalam struktur tubuh eceng gondok. Akan tetapi, jika kontaminan yang berlebihan dan telah melewati ambang batas akan mempercepat kematian pada tanaman eceng gondok itu sendiri (Rukmi, 2013)

- $\quad$ Adsorpsi

Hasil pengolahan pada perlakuan ke-II juga menghasilkan penurunan yang kecil. Dimana nilai rata-rata penurunan COD sebesar 233,6 mg/l, logam Fe sebesar 3,94 mg/l, dan logam $\mathrm{Pb}$ sebesar $0,043 \mathrm{mg} / \mathrm{l}$. Setelah didiamkan selama 24 jam dalam reaktor adsorpsi dengan menggunakan adsorben zeolit dan karbon aktif terjadi perubahan warna pada air limbah laboratorium yang awalnya berwarna merah menjadi warna jernih. Hal tersebut membuktikan bahwa karbon aktif mampu menyerap warna sehingga dapat menghilangkan warna limbah hasil koagulasi yang berwarna merah muda menjadi berwarna jernih (Azamia, 2012).

C. Efisiensi Penurunan

Limbah laboratorium lingkungan diolah menggunakan kombinasi proses kimia dan biologi. Proses tersebut digunakan untuk menurunkan parameter pencemar yaitu COD, $\mathrm{Fe}$ dan $\mathrm{Pb}$ agar dapat sesuai dengan baku mutu yang diperbolehkan untuk dibuang ke lingkungan. Berikut tabel efisiensi penurunan parameter pengolahan pada perlakuan keI dan perlakuan ke-II : 
Tabel 4 Efisiensi Penurunan pada Perlakuan Ke-I

\begin{tabular}{|c|c|c|c|c|c|}
\hline \multirow[b]{2}{*}{$\begin{array}{l}\text { Parameter } \\
\text { (mg/l) }\end{array}$} & \multirow[b]{2}{*}{ Ulangan } & \multicolumn{2}{|c|}{ Konsentrasi Parameter (mg/l) } & \multirow[b]{2}{*}{$\begin{array}{c}\text { Efisiensi } \\
\text { Penurunan } \\
\text { (\%) }\end{array}$} & \multirow[b]{2}{*}{$\begin{array}{l}{ }^{*} \text { Baku } \\
\text { Mutu }\end{array}$} \\
\hline & & $\begin{array}{c}\text { Sebelum } \\
\text { Proses } \\
\text { Pengolahan } \\
\end{array}$ & $\begin{array}{c}\text { Setelah } \\
\text { Proses } \\
\text { Pengolahan }\end{array}$ & & \\
\hline & 1 & 1617,1 & 150,1 & $91 \%$ & \\
\hline \multirow[t]{2}{*}{ COD } & 2 & 1617,1 & 125,0 & $92 \%$ & 100 \\
\hline & 3 & 1617,1 & 210,7 & $87 \%$ & \\
\hline \multirow[t]{2}{*}{ Rata-rata } & & 1617,1 & 161,9 & $89 \%$ & \\
\hline & 1 & 12,6 & 2,59 & $79 \%$ & \\
\hline \multirow[t]{2}{*}{$\mathrm{Fe}$} & 2 & 12,6 & 2,72 & $78 \%$ & 5 \\
\hline & 3 & 12,6 & 2,45 & $80 \%$ & \\
\hline \multirow[t]{2}{*}{ Rata-rata } & & 12,6 & 2,59 & $79 \%$ & \\
\hline & 1 & 6,75 & 0,100 & $98 \%$ & \\
\hline \multirow[t]{2}{*}{$\mathrm{Pb}$} & 2 & 6,75 & 0,003 & $99 \%$ & 0,1 \\
\hline & 3 & 6,75 & 0,089 & $98 \%$ & \\
\hline Rata-rata & & 6,75 & 0,064 & $99 \%$ & \\
\hline
\end{tabular}

Berdasarkan Tabel 4 dapat diketahui bahwa pengolahan limbah pada perlakuan ke-I memiliki efisiensi rata-rata diatas 70\%. Akan tetapi, meskipun memiliki efisiensi yang tinggi proses pengolahan pada perlakuan ke-I belum dapat menurunkan parameter COD yang terdapat dalam limbah Laboratorium Lingkungan Fakultas Teknik. Hal tersebut dipengaruhi oleh proses pengadukan yang masih menggunakan pengadukan secara manual pada proses koagulasi. Sehingga flok-flok yang terbentuk dalam proses koagulasi tidak tampak karena proses pengadukan yang dilakukan secara manual. Berikut tabel efisiensi penurunan pada prlakuan ke-II :

Tabel 5 Efisiensi Penurunan pada Perlakuan Ke-II

\begin{tabular}{cccccc}
\hline \multirow{2}{*}{$\begin{array}{c}\text { Parameter } \\
(\mathbf{m g} / \mathrm{l})\end{array}$} & Ulangan & $\begin{array}{c}\text { Sebelum } \\
\text { Proses } \\
\text { Pengolahan }\end{array}$ & $\begin{array}{c}\text { Setelah } \\
\text { Proses } \\
\text { Pengolahan }\end{array}$ & $\begin{array}{c}\text { Efisiensi } \\
\text { Penurunan } \\
\text { (\%) }\end{array}$ & *Baku \\
Mutu \\
COD & 1 & 1635,3 & 256,2 & $84 \%$ & \\
\hline Rata-rata & 2 & 1635,3 & 244,1 & $85 \%$ & 100 \\
\hline & 3 & 1635,3 & 200,5 & $87 \%$ & \\
\hline Fe & 1 & 1635,3 & 233,6 & $86 \%$ & 5 \\
\hline Rata-rata & 2 & 8,46 & 4,71 & $44 \%$ & \\
\hline & 3 & 8,46 & 4,09 & $52 \%$ & \\
\hline Pb & 1 & 8,46 & 3,01 & $64 \%$ & \\
\hline Rata-rata & & 8,46 & 3,94 & $53 \%$ & \\
\hline
\end{tabular}

*PERMEN LH No 5 Tahun 2014 
Berdasarkan Tabel 5 dapat diketahui bahwa nilai parameter COD masih melebihi baku mutu dan memiliki efisiensi rata-rata sebesar $86 \%$. Selain itu, efisiensi penurunan rata-rata parameter Fe pada perlakuan ke-II lebih rendah daripada perlakuan ke-I yaitu sebesar $53 \%$, sedangkan efisiensi rata-rata parameter $\mathrm{Pb}$ sama dengan efisiensi rata-rata pada perlakuan ke-I yaitu sebesar 99\%. Hal tersebut dapat dipengaruhi oleh urutan proses pengolahan, dimana pada perlakuan ke-II proses adsorpsi dilakukan setelah proses fitoremediasi, sehingga tanaman yang digunakan dalam proses fitoremediasi lebih cepat mati karena langsung terpapar oleh limbah yang telah melalui proses koagulasi sebelum melalui proses adsorpsi terlebih dahulu seperti pada perlakuan ke-I. Menurut Oppelt (2000), hal tersebut karena logam merupakan salah satu faktor penghambat pertumbuhan eceng gondok yang menyebabkan tumbuhan tersebut cepat mati saat digunakan dalam proses fitoremediasi.

D. Analisis Data Statistik Non Parametrik dengan Jenis Metode Uji Mann Whitney Menggunakan Minitab 14

Hasil pengolahan setiap parameter dari dua perlakuan selanjutnya dianalisis dengan uji statitiska. Jenis metode statistik yang digunakan yaitu uji Mann Whitney. Uji Mann Whitney merupakan uji non parametrik yang digunakan untuk menguji apakah dua buah sampel independen berasal dari populasi yang sama (Gio dan Elly, 2016). Hipotesis awal $\left(\mathrm{H}_{0}\right)$ dalam penelitian ini yaitu pengolahan limbah laboratorium dengan kombinasi proses kimia dan biologi menggunakan perlakuan ke-l lebih efektif daripada perlakuan ke-II dalam menurunkan parameter $\mathrm{COD}$, Fe dan $\mathrm{Pb}$, sedangkan hipotesis alternatif $\left(\mathrm{H}_{1}\right)$ yaitu pengolahan limbah laboratorium dengan kombinasi proses kimia dan biologi menggunakan perlakuan ke-I tidak lebih efektif daripada perlakuan ke-II.

Berdasarkan hasil uji Mann Whitney menggunakan Minitab 14 pada parameter COD diperoleh nilai signifikansi sebesar 0,1904 dimana nilai tersebut lebih besar dari batas kritis yaitu 0,05 sehingga keputusan hipotesis menerima hipotesis awal $\left(\mathrm{H}_{0}\right)$. Hal tersebut menunjukan bahwa tidak ada perbedaan nyata antara perlakuan ke-I dan perlakuan ke-II pada parameter COD, untuk parameter Fe hasil uji menunjukan bahwa nilai signifikansi yang diperoleh yaitu sebesar 0,0809 sehingga pada uji statistik parameter Fe tidak terdapat perbedaan nyata antara perlakuan ke-I dan perlakuan ke-II dalam penurunan parameter Fe, sedangkan untuk parameter $\mathrm{Pb}$ hasil uji Mann Whitney dengan nilai signifikansi yang diperoleh yaitu 1,000. Nilai tersebut menunjukan bahwa tidak terdapat perbedaan yang bermakna antara variabel perlakuan ke-I dan perlakuan ke-ll.

\section{KESIMPULAN}

Berdasarkan penelitian yang telah dilakukan, maka dapat disimpulkan beberapa hal sebagai berikut:

- Limbah Laborataorium Lingkungan Fakultas Teknik pada perlakuan ke-I (netralisasi, koagulasi, adsorpsi, dan fitoremediasi) sebelum pengolahan mengandung COD sebesar 1617,1 mg/l, Fe sebesar 12,59 mg/l, dan Pb sebesar 6,75 mg/l serta pH 1,3, sedangkan pada perlakuan ke-II (netralisasi, koagulasi, fitoremediasi dan adsorpsi) memiliki nilai COD sebesar 1635,3 mg/l, Fe sebesar 8,46 dan Pb sebesar 7,36 mg/l serta memiliki nilai pH sebesar 1,2.

- Pengolahan Limbah Laboratorium Lingkungan Fakultas Teknik dengan Kombinasi Proses Kimia dan Biologi pada perlakuan ke-I (netralisasi, koagulasi, adsorpsi, dan fitoremediasi) memiliki efektivitas rata-rata dalam penurunan parameter COD sebesar $89 \%$ yaitu dari $1617,1 \mathrm{mg} / \mathrm{l}$ menjadi $161,9 \mathrm{mg} / \mathrm{l}$, logam Fe $79 \%$ dari $12,6 \mathrm{mg} / \mathrm{l}$ menjadi $2,59 \mathrm{mg} / \mathrm{l}$ dan logam $\mathrm{Pb}$ sebesar $99 \%$ dari $6,75 \mathrm{mg} / \mathrm{l}$ menjadi $0,064 \mathrm{mg} / \mathrm{l}$. Sedangkan pada perlakuan ke-II (netralisasi, koagulasi, fitoremediasi dan adsorpsi) efektivitas rata-rata penurunan COD yaitu sebesar $86 \%$ dari $1635,3 \mathrm{mg} / \mathrm{l}$ menjadi 
233,6 mg/l, logam Fe 53\% dari 8,46 mg/l menjadi 3,94 mg/l dan logam $\mathrm{Pb}$ sebesar $99 \%$ dari $7,36 \mathrm{mg} / \mathrm{l}$ menjadi $0,043 \mathrm{mg} / \mathrm{l}$. pH limbah yang dihasilkan pada perlakuan ke-I dari 1,3 menjadi 7,8 dan pada perlakuan ke-II dari 1,2 menjadi 7,8.

- Penerapan kedua metode pengolahan limbah cair memberikan hasil yang sama.

\section{UCAPAN TERIMA KASIH}

Puji syukur saya panjatkan kepada Tuhan Yang Maha Esa serta tidak lupa saya ucapkan terima kasih kepada dosen pembimbing skripsi saya, Bapak Arifin dan Ibu Lia Destiarti serta dosen penguji saya Ibu Isna Apriani dan Bapak Hendri Sutrisno serta teman-teman yang telah membantu dalam menyelesaikan tugas akhir saya. Semoga penelitian ini dapat bermanfaat bagi semua pihak.

\section{DAFTAR PUSTAKA}

Audiana, M. 2017. Pengolahan Limbah Cair Laboratorium Teknik Lingkungan dengan Koagulasi dan Adsorpsi untuk Menurunkan COD, $\mathrm{Fe}$, dan Pb. Pontianak: Universitas Tanjungpura.

Azamia, M. 2012. Pengolahan Limbah Cair Laboratorium Kimia dalam Penurunan Kadar Organik Serta Logam Berat Fe, Mn, Cr dengan Metode Koagulasi dan Adsorpsi. Depok: Universitas Indonesia.

Aziz, T.; Pratiwi, Y dan Rethiana, L. 2013. Pengaruh Penambahan Tawas $\left(\mathrm{Al}_{2}\left(\mathrm{SO}_{4}\right)_{3}\right.$ dan Kaporit $\mathrm{Ca}(\mathrm{OCl})_{2}$ Terhadap Karakteristik Fisik dan Kimia Air Sungai Lambidaro. Jurnal Teknik Kimia No.3 Vol.19.

Environmental Protection Agency. 2000. Introduction to Phytoremediation. National Risk Management Research Laboratory Office of Research and Development. U.S. Environmental Protection Agency. Ohio.

Gio, P.U.; dan Elly, R. 2016. Belajar Olah Data dengan SPSS, Minitab, R, Microsoft Excel, Eviews, Lisrei, Amos, dan Smartpls. Medan. USU.

Hendra, R. 2008. Pembuatan Karbon Aktif Berbahan Dasar Batu Bara Indonesia dengan Metode Aktivasi Fisika dan Karakteristiknya. Departemen Teknik Mesin. UI.

Oppelt, T.E. 2000. Introduction to Phytoremediation. National Risk Management Research Laboratory. United States Environmental Protection Agency.

Peraturan Menteri Lingkungan Hidup Republik Indonesia Nomor 5 Tahun 2014 Tentang Baku Mutu Air Limbah.

Prayitno; Kismolo, E.; dan Nurimaniwathy. 2006. Kajian Pemanfaatan Zeolit Alam pada Reduksi Kadar Pb dan Cd dalam Limbah Cair. Prosiding PPI-PDIPTN 2005. Pusat Teknologi Akselerator dan Proses Bahan-bahan. Yogyakarta.

Rukmi, D. P. 2013. Efektivitas Eceng Gondok (Eichhornia crassipes) dalam Menurunkan Kadar Deterjen, BOD, dan COD pada Air Limbah Laundry (Studi di Laundry $X$ di Kelurahan Jember Lor Kecamatan Patrang Kabupaten Jember). Jember: Universitas Jember.

Setiaka, J; Ulfin, I dan Widiastuti, N. 2010. Adsorpsi Ion Logam Cu (II) dalam Larutan pada Abu Dasar Batu Bara Menggunakan Metode Kolom. Prosiding Kimia FMIPA. ITS.

Sutapa, I.D.A. 2014. Perbandingan Efisiensi Koagulan Poli Alumunium Khlorida dan Alumunium Sulfat dalam Menurunkan Turbiditas Air Gambut dari Kabupaten Katingan Kabupaten Provinsi Kalimantan Tengah. Ris. Geo. Tam Vol. 24, No.1 (1221). 